\title{
Políticas públicas de inclusão educacional: desafios e perspectivas
}

\section{Public policies of educational inclusion: challenges and perspectives}

\author{
Angelina Carmela Romão Mattar Matiskei*
}

\begin{abstract}
RESUMO
O presente trabalho pretende acirrar o debate atual acerca dos movimentos sociais em favor da inclusão escolar de alunos com necessidades educacionais especiais, situando o papel do Estado, com destaque à Secretaria de Estado da Educação, na implementação de políticas públicas, nesse contexto. Cabe ao Estado a tarefa de buscar novos caminhos para a superação de alguns obstáculos presentes no seio social que distanciam os grupos excluídos do acesso aos bens e serviços e, no caso específico da inclusão escolar, do direito à educação. Para tanto, apresentam-se as principais tendências educacionais em relação a um novo significado da Educação Especial no contexto histórico da inclusão e às ações implementadas pelo Departamento de Educação Especial na promoção dos direitos sociais dos alunos com necessidades educacionais especiais. Uma vez que a terminologia "necessidades educacionais especiais" apresenta uma ampla abrangência, podendo sugerir que a maioria dos alunos encontra-se nela contemplada, apresenta-se uma breve exposição da concepção de necessidades educacionais especiais adotada pela Seed/DEE, na proposição de suas políticas e na definição do alunado, alvo desse conjunto de ações. Nossa meta é desenvolver e implementar políticas públicas cujo propósito esteja assentado no respeito à diferença e no compromisso com a promoção dos direitos humanos.
\end{abstract}

Palavras-chave: educação especial, políticas públicas, inclusão escolar.

* Formada em Direito pela UFPR. Especialista pela Escola Superior do Ministério Público. Chefe do Departamento de Educação Especial da Secretaria de Estado da Educação do Paraná. 


\begin{abstract}
The purpose of this work is to incite the current debate concerning the social movements in behalf of educational inclusion of students with special educational needs, pointing out the role of the State, with prominence to the state Education Bureau, in the implementation of public policies, in this context. The State is responsible for the task of searching for new ways to surpass some of the obstacles in social scope, which turns the excluded groups far from the access to goods and services especially in the task of educational inclusion, the right to education. For that we present the main educational trends in relation to a new meaning of Special Education, in the historical context of social inclusion and implemented actions made by the Special Education Department, to promote social rights to students who have special educational needs. Considering that the terminology "Special Educational Needs" has a large scope and suggests that the majority of students are contemplated in that, we present a brief exposition about the conception of special educational needs adopted by the State Education Bureau/Special Education Department, aiming at proposing policies and defining the students group that is the purpose of this action. Our goal is to develop and to implement public policies, aiming at the respect for the differences and the commitment to the promotion of human rights.
\end{abstract}

Key-words: special education, public policies, educational inclusion.

\title{
Introdução
}

O debate sobre a questão das políticas públicas de inclusão escolar passa, necessariamente, pela reflexão mais ampla sobre os grupos que têm sido localizados nos discursos correntes da exclusão social.

Muito se tem falado de exclusão social na atualidade, e o tema catalisa, de maneira surpreendente, um número cada vez maior de grupos marginalizados que integram as fronteiras da exclusão social.

Entende-se que, independentemente da expressão que adjetive o substantivo educação - 'inclusiva', 'para todos' ou 'multicultural' -, a realidade que se pretende modificar é aquela que expropria os direitos cidadãos da plena inserção social dos sujeitos.

Em acepção ampla, portanto, pensar em políticas públicas de inclusão escolar significa planejar e implementar projetos que ampliem as possibilida- 
des de acesso e inserção social dos diferentes grupos marginalizados, seja por sua situação de pobreza extrema, por sua condição de cor, raça e etnia, por diferenciações em sua compleição física ou cognitiva, por vulnerabilização por sua escolha política, religiosa ou de orientação sexual, entre tantas outras possibilidades. Ou seja, o leque da exclusão social é tão grande quanto são os mecanismos de imposição de padrões de normalidade aos quais a humanidade esteve submetida historicamente, que preconizam modelos estéticos, de inteligência, de linguagem, de condição econômica e cultural, com que devemos nos conformar, sob o risco de engrossarmos as fileiras dos excluídos socialmente.

Inclusão e exclusão são facetas de uma mesma realidade: discutir mecanismos para viabilizar a inclusão social, econômica, digital, cultural ou escolar significa admitir a lógica intrinsecamente excludente presente nos atuais modos de organização e produção social que se querem modificar.

Cabe ao Estado, nesse contexto, a tarefa de buscar novos caminhos para a superação de alguns dos obstáculos presentes no seio social que distanciam os segmentos excluídos do acesso aos bens e serviços e, no caso específico da inclusão escolar, do direito à educação.

Dessa forma, a Secretaria de Estado de Educação, aqui representada por intermédio de seu Departamento de Educação Especial, tem como horizonte a construção de "um Estado concentrado em funções estratégicas para a sociedade e com um desenho institucional e um desenvolvimento de capacidades gerenciais que lhe permitam concretizá-las com alta eficiência" (KLIKSBERG, 1998, p. 45). Enfim, um Estado com papel de alta relevância no desenvolvimento do campo social, conectado com as novas fronteiras tecnológicas em desenvolvimento institucional e de gestão.

Para tanto, neste trabalho, pretendemos situar nosso posicionamento na proposição das políticas educacionais voltadas a assegurar o direito a uma educação de qualidade para todos os alunos, com destaque àqueles que apresentam necessidades educacionais especiais.

\section{Políticas públicas e inclusão social}

O avanço na conquista de direitos dos grupos excluídos passa pela superação da desarticulação das políticas públicas de base na área social, como a educação, a saúde, família, habitação, desenvolvimento social, a fim de que 
possamos resgatar a unidade nas ações, sabedores que somos de que, nessa área, nenhuma ação individual consegue atingir metas globais sem o necessário respaldo de um trabalho em rede. O Estado, nesse sentido, será o mediador entre diferentes instâncias e segmentos sociais para a integração entre regiões e municípios, ONGs, fundações, empresas privadas, movimentos sindicais, organizações religiosas, Instituições de Ensino Superior, entre outros setores da sociedade civil e comunidades organizadas (KLIKSBERG, 1998) na implementação de ações que assegurem os direitos de todos os cidadãos e, em especial, daqueles que sofrem discriminação ou são marginalizados por diferentes razões.

Para cumprir esse papel com eficiência, objetivando um impacto social efetivo nos injustificáveis processos de exclusão social a que têm sido submetidos diversos grupos da sociedade civil, há necessidade de uma releitura das políticas públicas em andamento.

É necessário admitir que as políticas públicas não são pensadas apenas a partir de determinações jurídicas, legais, nas quais o Estado aparece como mero executor, neutro, destituído de princípios axiológicos que balizam a sua ação. Mesmo sendo as políticas públicas definidas tendo como parâmetro o bem comum de todos os segmentos sociais, deve-se perceber a dinâmica conflitiva dos diferentes interesses e forças envolvidos no tecido social (BONETI, 2000).

O perfil de configuração que caracteriza a sociedade atual, marcado por um projeto econômico e político global, impõe-se e determina no contexto sociocultural mudanças significativas, comprometidas com essa lógica de organização e produção. Os valores postos na sociedade moderna do neoliberalismo denunciam a ênfase no indivíduo, na competitividade, na conformação às competências exigidas para o mundo do trabalho.

Mesmo pressionadas, as instituições sociais buscam espaço para o exercício da contestação da ordem dominante, propondo sua superação. A escola, como instituição social imersa nesse contexto, "é sempre lembrada como uma instituição encarregada da promoção da inclusão ou da diminuição da exclusão social" (BONETI, 2000, p. 213), pois tem seu cotidiano permeado pelas mesmas práticas, conflitos e teses presentes na sociedade em geral. É na escola que a gestão educacional faz ecoar os seus princípios, é nela que se materializam as políticas e os programas governamentais.

Apesar das limitações e possibilidades que a conjuntura das políticas neoliberais presentes na sociedade imputam à escola, ela segue ocupando papel de destaque no contexto da inclusão social, cuja gestão deve estar comprometida com a formação do sujeito social, fortalecendo e construindo identidades locais. 
Imersa no projeto neoliberal, à escola sobra o compromisso paradoxal de lidar com duas realidades intrinsecamente contraditórias. Define-se seu papel formador de adequação de hábitos, atitudes, 'competências e habilidades', dos padrões de excelência ${ }^{1}$ exigidos pelo mercado, que definem a competência técnica do sujeito, fundamentado em um padrão homogêneo de comportamento e de conhecimento, ignorando-se as diferenciações culturais e socioeconômicas presentes no contexto do qual se originam esses sujeitos (вONETI, 2000). Ao mesmo tempo em que lhe cabe formar o sujeito social, afinado com as novas demandas do mercado consumidor, cabe-lhe, também, oferecer respostas ao grande número de 'desqualificados' que, por várias contingências, estiveram excluídos do acesso ao conhecimento técnico exigido pelo mercado e que não se enquadram nos limites impostos pelo projeto hegemônico do capitalismo mundial.

É nesse aspecto que se encontra o grande desafio da escola. A busca da homogeneidade, que confere com os propósitos do projeto econômico e político global, mas compromete o papel da escola na luta pela inclusão social dos diferentes e dos segmentos sociais com menor capacidade de enfrentamento da competitividade (...) (BONETI, 2000, p. 238-239).

Compete à educação e à escola, nesse sentido, ser um meio de contestação da ordem dominante, trabalhando para a superação de projetos políticopedagógicos que conformem os sujeitos aos padrões de exclusão decorrentes do processo capitalista de produção. Criar espaços para que o modelo dominante seja problematizado, com vistas a sua superação, é o compromisso que cabe à escola, ainda que ela não detenha todas as armas para a transformação das relações vigentes.

É justamente no bojo dessas contradições que o Departamento de Educação Especial situa o seu compromisso em desenvolver e implementar políticas públicas, cujo propósito esteja assentado no respeito à diferença e na promoção dos direitos humanos. Com efeito, entende-se que

${ }^{1}$ BONETI (2000) define na expressão 'excelência' o projeto social neoliberal que expressa a idéia de competitividade associada à capacidade da lida com a inovação tecnológica presente nos meios de produção da sociedade capitalista. 
a consciência do direito de constituir uma identidade própria e do reconhecimento da identidade do outro traduz-se no direito à igualdade e no respeito às diferenças, assegurando oportunidades diferenciadas (eqüidade), tantas quantas forem necessárias, com vistas à busca da igualdade. O princípio da eqüidade reconhece a diferença e a necessidade de haver condições diferenciadas para o processo educacional (Parecer CNE n. $\left.{ }^{\circ} 017 / 2001\right)^{2}$.

A Secretaria de Estado da Educação define sua proposta político-pedagógica retomando a centralidade da escola e do professor na gestão das políticas educacionais no Estado do Paraná, tendo como principais linhas de ação a reformulação curricular, a construção de um novo Plano Estadual de Educação e a efetivação da política de formação continuada dos profissionais da Educação.

É nosso objetivo desenvolver um amplo "projeto de reformulação curricular que tenha como base a elaboração coletiva de um conjunto de idéias que permeiem as propostas que estarão na base do processo do ensinar e do aprender nas escolas" (ARCO-VERDE, 2004, p. 2).

Sabe-se que as políticas curriculares são espaços públicos de tomada de decisões, atravessados por lutas ideológicas, por pontos de vista contraditórios que refletem a dinâmica do movimento social. Os textos curriculares simbolizam o discurso oficial do Estado, porém são legitimados pelos diferentes atores sociais que os colocam em prática, sobretudo aqueles que se situam no contexto da escola.

Dessa forma, à Educação Especial do Estado do Paraná caberá desencadear um amplo debate, a fim de redimensionar os fundamentos e concepções que norteiam o fazer pedagógico das escolas, uma vez que currículos flexíveis, abertos e dinâmicos, que permitam o acolhimento de todas as diferenças presentes no contexto escolar, constituem um fundamento essencial à inclusão. Essa construção coletiva estará refletida no Plano Estadual de Educação, em fase de elaboração.

Aliada à ação da reformulação curricular está a de promover a formação continuada dos profissionais da Educação, de modo a permitir a reflexão sobre os desafios que se impõem à prática pedagógica, em face da diversidade de necessidades apresentadas pelos alunos em sala de aula.

${ }^{2}$ Diretrizes Nacionais para a Educação Especial na Educação Básica. 
Procuraremos consolidar a intenção de que as necessidades educacionais especiais não sejam discutidas apenas pelos profissionais da Educação Especial. Todos os eventos programados pela Secretaria de Estado da Educação, que prevêem a participação de professores, alunos e demais representantes das comunidades escolares de todo o Estado do Paraná, contemplam a discussão de temas relacionados à Educação Especial, seja sob a forma de oficinas ou mesmo de eixos temáticos que compõem a programação dos eventos.

Soma-se a isso o programa de formação continuada de professores do ensino regular e especial, específico do Departamento de Educação Especial, o qual tem como eixos norteadores de sua proposta temas voltados às especificidades do processo educacional de alunos com necessidades educacionais especiais.

Acreditamos, dessa forma, estar oferecendo subsídios que ampliem as possibilidades de reflexão e intervenção no fazer pedagógico, pois

inclusão e exclusão começam na sala de aula. Não importa o quão comprometido um governo possa ser com relação à inclusão; são as experiências cotidianas das crianças nas salas de aulas que definem a qualidade de sua participação e a gama total de experiências de aprendizagem oferecidas em uma escola. As formas através das quais as escolas promovem a inclusão e previnem a exclusão constituem o cerne da qualidade de viver e aprender experimentado por todas as crianças (MITTLER, 2003, p. 139).

\section{Educação para Todos: um projeto em construção}

Durante a década de 90, a Educação para Todos, concebida em Jomtien - Tailândia, serviu de marco para o delineamento e a execução de políticas educativas no mundo inteiro, e consolidou-se como um conceito presente nas agendas dos diferentes governos para a garantia de acesso e permanência na Educação Básica, por meio da satisfação das necessidades básicas de aprendizagem de crianças, jovens e adultos oriundos de diferentes grupos e culturas (TORRES, 2001).

Jomtien e as propostas de Educação para Todos que a seguiram, com destaque à Declaração de Salamanca, foram extremamente significativas, pois 
garantiram o imprescindível espaço para uma ampla discussão sobre a necessidade de os governos contemplarem propostas que reconhecessem a diversidade dos alunos e os meios e modos para garanti-las, o que resultou em um compromisso da maioria deles para trabalhar pela inclusão educacional.

Tomar o tema da inclusão escolar e o papel da Educação Especial, nesse contexto, exige, em um primeiro momento, situar o nosso posicionamento em relação ao entendimento dos sujeitos envolvidos nessa ação que, historicamente, foram qualificados como 'excepcionais', 'deficientes' e atualmente são definidos pela expressão 'necessidades educacionais especiais'.

É histórico o fato de a Educação Especial ser definida como um 'tipo' de educação voltada ao atendimento de pessoas com deficiência as quais necessitam de cuidados clínicos e terapêuticos, em função das alterações orgânicas (e limitações delas decorrentes) que apresentam. Desse modo, o adjetivo especial da educação sempre esteve relacionado à 'clientela' ${ }^{3}$ a que se destinavam os atendimentos prestados por essa modalidade de educação (EDLER CARVALHO, 2001).

Com a mudança de concepção sinalizada na Lei de Diretrizes e Bases da Educação Nacional 9394/96, aponta-se um novo significado da Educação Especial, ampliando-se não apenas o seu escopo de atuação, como também o público-alvo a que se destina.

Essa nova perspectiva encontra-se sintetizada nas palavras de EDLER CARVALHO (2001, p. 17) para a qual "especiais devem ser consideradas as alternativas educativas que a escola precisa organizar, para que qualquer aluno tenha sucesso; especiais são as estratégias que a prática pedagógica deve assumir para remover barreiras para a aprendizagem".

Desse modo, desloca-se o enfoque do especial ligado ao aluno para o enfoque do especial atribuído à Educação. Mesmo que os alunos apresentem características diferenciadas decorrentes não apenas de quadros orgânicos vinculados a deficiências ou distúrbios invasivos de desenvolvimento, mas, também, de condições socioculturais diversas e econômicas desfavoráveis, eles terão direito a receber apoios diferenciados daqueles normalmente oferecidos pela educação escolar. Assim, caracterizam-se as necessidades educacionais especiais, que estarão, por um lado, vinculadas às características de aprendizagem diferenciadas apresentadas por alguns alunos e, por outro, ao conjunto de recursos, apoios e serviços especializados tornados disponíveis pelos sistemas de ensino.

${ }^{3} \mathrm{O}$ termo clientela tem um significado pejorativo, já que remete a cliente, em lugar de aluno. 
Esse novo ponto de vista sinaliza para a necessária revitalização dos projetos político-pedagógicos em andamento nas escolas e da provisão de recursos humanos, técnicos e materiais ofertados pelos sistemas de ensino, como também traz em seu bojo implicações importantes de natureza políticoadministrativa, uma vez que são ampliados, significativamente, os tradicionais limites relacionados ao alunado beneficiado pelos serviços oferecidos por essa modalidade de educação (MARCHESI; MARTIN, 1995).

Uma vez que a terminologia "necessidades educacionais especiais" pode ser atribuída a diferentes grupos de educandos, desde aqueles que apresentam deficiências permanentes até aqueles que, por razões diversas, fracassam em seu processo de aprendizagem escolar, sua ampla abrangência poderia sugerir que a maioria dos alunos encontra-se dentro dela, haja vista as atuais e alarmantes estatísticas demonstrando os índices de evasão e fracasso escolar.

Essa modificação substancial do enfoque e suas implicações operaram a mudança nas representações sobre os problemas de aprendizagem dos alunos e geraram uma série de discussões relacionadas à necessidade de os sistemas de ensino implementarem macropolíticas que atendessem às necessidades educacionais especiais dos alunos, estendendo-se os domínios do especial em educação não apenas para os setores que, de forma institucionalizada, eram responsáveis pelos serviços destinados a esse grupo de alunos.

A Secretaria de Estado de Educação do Paraná, imbuída desse espírito, desenvolve vários projetos que enfocam a inclusão social e a promoção da cidadania de crianças, jovens e adultos. Soma-se a isso o trabalho do Departamento de Educação Especial que, seguindo as determinações do Conselho Nacional de Educação (Res. CNE/CEB n. ${ }^{\circ}$ 02/2001 e Parecer CNE/CEB n. ${ }^{\circ}$ 017/2001) e a tendência assumida por outros sistemas de ensino, nacionalmente, desenvolve ações destinadas aos alunos com necessidades educacionais temporárias e permanentes, conforme prevê o artigo $6^{\circ}$ da recente Deliberação n. ${ }^{\circ}$ 02/2003, do Conselho Estadual de Educação, que estabelece normas para a educação especial no sistema de ensino do Estado do Paraná:

Art. $6^{\circ}$ Será ofertado atendimento educacional especializado aos alunos com necessidades educacionais especiais decorrentes de:

I. dificuldades acentuadas de aprendizagem ou limitações no processo de desenvolvimento que dificultem o acompanhamento das atividades curriculares, não vinculadas a uma causa orgânica específica ou relacionadas a distúrbios, limitações ou deficiências;

II. dificuldades de comunicação e sinalização demandando a utilização de outras línguas, linguagens e códigos aplicáveis; 
III. condutas típicas de síndromes e quadros psicológicos neurológicos ou psiquiátricos;

IV. superdotação ou altas habilidades que, devido às necessidades e motivações específicas, requeiram enriquecimento, aprofundamento curricular e aceleração (...).

O deslocamento no que diz respeito à concepção de Educação Especial, e à maneira como os serviços especializados devam ser oferecidos, contribuiu para consolidar uma nova perspectiva de atuação dessa modalidade de ensino na ampla rede de apoio ao aluno com necessidades educacionais especiais.

Segundo a compreensão dada pelas Diretrizes Nacionais para a Educação Especial na Educação Básica,

por Educação Especial, modalidade da educação escolar, entende-se um processo educacional definido em uma proposta pedagógica, assegurando um conjunto de recursos e serviços educacionais especiais, organizados institucionalmente para apoiar, complementar, suplementar e, em alguns casos, substituir os serviços educacionais comuns, de modo a garantir a educação escolar e promover o desenvolvimento das potencialidades dos educandos que apresentam necessidades educacionais especiais, em todos os níveis, etapas e modalidades da educação (Res. CNE/CEB n. 02/2001).

Esse ponto de vista amplia sua abrangência e possibilidades de inserção no contexto geral de educação, afastando-a definitivamente do lugar de subsistema paralelo e menor que historicamente lhe foi destinado na organização dos sistemas de ensino.

Obviamente essa compreensão está vinculada à mudança de perspectiva nos paradigmas que sustentavam a Educação Especial, cujo centro de atuação repousava na perspectiva das limitações funcionais dos educandos e suas possibilidades de reabilitação em serviços especializados paralelos, que lhes devolvessem a oportunidade de integração às escolas regulares. O divórcio entre os serviços educacionais especializados e regulares condenava a escolarização do aluno à opção definitiva e mutuamente excludente por um dos contextos de ensino. 
A possibilidade de integração entre ambos os serviços, uma vez que é no contexto regular de ensino que serão buscadas, preferencialmente, as respostas às suas necessidades educacionais especiais, abriu a perspectiva de reorganização e adaptação dos ambientes educacionais comuns: eliminação de barreiras arquitetônicas, apoio de profissionais especializados, flexibilização curricular e adaptações curriculares de pequeno e grande porte, por exemplo.

Isso posto, depreende-se que há, nessa gestão da SEED, um compromisso do sistema educacional como um todo, e não apenas de parte dele - a Educação Especial -, em responsabilizar-se com a inclusão educacional de todos os alunos, e não apenas de parte deles - alunos com deficiências.

O Departamento de Educação Especial é o órgão responsável, no Estado, pela orientação da política de atendimento às pessoas com necessidades educacionais especiais, em cumprimento aos dispositivos legais e filosóficos estabelecidos na esfera federal e em consonância com os princípios norteadores da Secretaria de Estado da Educação do Paraná.

Em recente levantamento de dados sobre a cobertura da Educação Especial no Paraná, referente ao ano de 2003, observa-se que, dos 399 municípios do Estado do Paraná, 367 ofertam algum tipo de atendimento educacional especializado, o que se traduz no percentual significativo de $92 \%$ de cobertura. Dos 58.730 alunos beneficiados, 38.190 são atendidos pela rede conveniada (escolas especiais) e 20.540 pela rede regular de ensino com apoios pedagógicos especializados (tabela 1).

TABELA 1 - DADOS ATUALIZADOS DA EDUCAÇÃO ESPECIAL - JAN/2004

\begin{tabular}{|c|c|c|c|c|c|}
\hline \multicolumn{6}{|c|}{ Dados atualizados da Educacão Especial - jan/2004 } \\
\hline ESCOLAS & N. ${ }^{\circ}$ DE ALUNOS & \multicolumn{2}{|c|}{ N. ${ }^{\circ}$ DE PROFESSORES } & $\begin{array}{r}\mathrm{N}^{\circ} \\
\text { PROGRAM } \\
\text { Recursos, Class }\end{array}$ & $\begin{array}{l}\text { OLAS / } \\
\text { ECIAIS: Salas de } \\
\text { iais, PERAE e outros }\end{array}$ \\
\hline $\begin{array}{c}\text { ENSINO } \\
\text { REGULAR }\end{array}$ & 20.540 & \multicolumn{2}{|c|}{291 (QPM/ESTADO) } & $\begin{array}{c}1.762 \\
\text { MUNICIPAIS }\end{array}$ & $\begin{array}{c}\mathbf{2 7 3} \\
\text { ESTADUAIS }\end{array}$ \\
\hline $\begin{array}{c}\text { ESCOLAS } \\
\text { ESPECIAIS }\end{array}$ & 38.190 & $681(\mathrm{QPM})$ & $\begin{array}{c}\mathbf{6 . 8 8 3} \\
\text { (REPASSE R\$) }\end{array}$ & ESCOL & VENIADAS \\
\hline
\end{tabular}

FONTE: DADOS DE ARQUIVO SEED/DEE 2004.

Os serviços e apoios pedagógicos especializados estão distribuídos entre as diferentes áreas de atendimento, compreendendo a oferta de salas de recursos, centros de atendimento especializado, apoio de intérpretes de língua de sinais para alunos surdos e professores de apoio em sala de aula regular para alunos com graves comprometimentos físico-motores, ou classes e escolas especiais (tabelas 2 e 3 ). 
TABELA 2 - SERVIÇOS E APOIOS ESPECIALIZADOS NA REDE REGULAR

\begin{tabular}{|c|c|c|c|c|c|c|c|c|c|c|}
\hline ÁREA & \multicolumn{2}{|c|}{ MENTAL } & \multicolumn{2}{|c|}{ SURDEZ } & \multicolumn{2}{|c|}{ VISUAL } & \multicolumn{2}{|c|}{ DEF. FÍSICA } & \multicolumn{2}{|c|}{$\begin{array}{l}\text { CONDUTAS } \\
\text { TÍPICAS }\end{array}$} \\
\hline ESFERA & $\mathrm{M}$ & E & $\mathrm{M}$ & E & M & E & $\mathrm{M}$ & $\mathrm{E}$ & $\mathrm{M}$ & $\mathrm{E}$ \\
\hline SALA DE RECURSOS & 469 & 78 & & & & & & & 5 & \\
\hline $\mathrm{CAE}$ & & & 198 & 8 & 147 & 18 & 2 & 4 & & \\
\hline CLASSE ESPECIAL & 904 & 151 & & & & & & & 8 & 1 \\
\hline $\begin{array}{l}\text { PROFESSOR- } \\
\text { INTÉRPRETE }\end{array}$ & & & & 29 & & & & & & \\
\hline PROFESSOR DE APOIO & & & & & & & & 1 & & \\
\hline Total de alunos atendidos & \multicolumn{2}{|c|}{16.321} & \multicolumn{2}{|c|}{1.484} & \multicolumn{2}{|c|}{2.617} & \multicolumn{2}{|c|}{31} & \multicolumn{2}{|c|}{87} \\
\hline
\end{tabular}

M - MUNICIPAL E - ESTADUAL CAE - CENTRO DE ATENDIMENTO ESPECIALIZADO FONTE: DADOS DE ARQUIVO SEED/DEE 2004.

TABELA 3 - ESCOLAS ESPECIAIS

\begin{tabular}{|c|c|c|c|c|}
\hline \multirow{2}{*}{ ÁREA } & \multicolumn{3}{|c|}{ ESFERA } & N. $^{\mathbf{0}}$ alunos \\
\cline { 2 - 5 } & $\mathrm{M}$ & $\mathrm{E}$ & $\mathrm{C}$ & Total \\
\hline MENTAL & 5 & & 314 & $\mathbf{3 2 . 7 5 1}$ \\
\hline SURDEZ & 3 & 2 & 14 & $\mathbf{2 . 5 2 6}$ \\
\hline VISUAL & & & 9 & $\mathbf{8 6 0}$ \\
\hline DEF. FÍSICA & & & 11 & $\mathbf{1 . 4 6 0}$ \\
\hline CONDUTAS TÍPICAS & & & 04 & $\mathbf{5 9 3}$ \\
\hline Total de alunos atendidos & & & & $\mathbf{3 8 . 1 9 0}$ \\
\hline
\end{tabular}

M - MUNICIPAL E - ESTADUAL C - CONVENIADA FONTE: DADOS DE ARQUIVO SEED/DEE 2004.

Os dados denunciam uma situação histórica, que se acentuou na última década, por ausência de ações efetivas do Estado em assumir suas responsabilidades quanto ao atendimento educacional especializado, preferencialmente, na Rede Pública de Ensino, delegando a oferta à rede conveniada. A inexistência de apoios e serviços especializados em todo o fluxo da escolarização (com destaque ao segundo segmento do Ensino Fundamental), a política inconsistente de formação continuada dos professores do ensino regular e a ausência de equipes multiprofissionais para prestar apoio à escolarização dos alunos com necessidades educacionais especiais foram, entre outros fatores, elementos que contribuíram para a exclusão do aluno na rede pública.

A inclusão educacional é um projeto gradativo, dinâmico e em transformação, que exige do Poder Público, em sua fase de transição, o absoluto respeito às diferenças individuais dos alunos e a responsabilidade quanto à oferta e manutenção dos serviços mais apropriados ao seu atendimento.

O compromisso do Departamento de Educação Especial está direcionado ao respeito às diferenças individuais dos alunos com necessidades educacionais especiais e prevê a continuidade da oferta de apoios e serviços especializados, tanto em contexto inclusivo, preferencialmente, quanto em "locus" específico (classes e escolas especiais). Promover o desenvolvimento das potencialidades dos alunos implica na avaliação permanente da 
efetividade dos serviços educacionais prestados, permitindo sua mobilidade entre as diferentes opções de apoios e serviços especializados ofertados.

É partindo desse princípio que entendemos que, embora a escola regular seja o local preferencial para promoção da aprendizagem e inclusão de crianças com necessidades educacionais especiais (e para isso estamos trabalhando), há uma parcela de alunos que, em função de seus graves comprometimentos ou necessidade de comunicação diferenciada, requerem atenção individualizada e adaptações curriculares significativas, os quais necessitam que seu atendimento seja realizado em classes ou escolas especiais.

Mesmo nesses casos, não há que se perder de vista a necessidade de um trabalho conjunto e interligado que se concretize interdisciplinarmente na aprendizagem da criança, de modo a não se caracterizarem dois processos distintos e desvinculados, ou seja, duas 'educações': a regular e a especial (EDLER CARVALHO, 2001).

A ampliação do número de alunos a serem atendidos no contexto da escola inclusiva está condicionada tanto ao redimensionamento dos projetos político-pedagógicos das escolas quanto à política de expansão de serviços de apoio no ensino regular, como professores-intérpretes de língua de sinais para alunos surdos, salas de recursos para apoio de alunos com deficiência mental matriculados de $5^{\mathrm{a}}$ a $8^{\mathrm{a}}$ séries e enriquecimento curricular para alunos com altas habilidades/superdotação, professores de apoio permanente para alunos com graves comprometimentos físico-motores e transtornos invasivos de desenvolvimento, entre outros. Dessa forma, muitos dos alunos atualmente atendidos em escolas especiais poderão migrar para o contexto regular de ensino, tendo seus direitos a uma educação de qualidade assegurados. Isso possibilitará a abertura de novas vagas em escolas especiais para muitos dos alunos com graves comprometimentos que se encontram em casa, sem qualquer tipo de atendimento.

Considerando-se que há ainda 32 municípios do Estado sem oferta de atendimento especializado de qualquer natureza, há iniciativas em andamento para a expansão dos serviços prestados, em ambos os contextos de ensino, preconizando o respeito à diversidade geopolítica e econômica dos municípios (baixo $\mathrm{IDH}^{4}$, extensão territorial, condições geográficas) e às necessidades educacionais especiais dos alunos. Desse modo, assumimos nossa responsabilidade de forma mais intensa, preenchendo lacunas existentes em função da omissão do Estado nos últimos anos.

\footnotetext{
${ }^{4}$ Índice de Desenvolvimento Humano.
} 
Entende-se que a inclusão escolar para alunos com necessidades educacionais especiais extrapola os limites dos muros da escola e exige um enfoque intersetorial de políticas de apoio que integre áreas como as da saúde, ação social e trabalho, a fim de que se possam melhorar as condições globais que atuam sobre a aprendizagem dos alunos, garantindo as condições objetivas e subjetivas básicas de que os alunos necessitam para aprender.

Diante deste contexto, é fundamental o fortalecimento das interfaces entre outros setores do Governo do Estado e parcerias com segmentos da sociedade civil organizada para estabelecer ações que efetivem o processo da inclusão escolar e avançar em direção à realização de conquistas que são fundamentais à consolidação do conceito de inclusão educacional, tal como é entendido.

O diálogo iniciado com esses setores sinaliza para a efetivação de algumas ações, dentre as quais destaca-se a implementação de um Termo de Cooperação Técnica junto à Secretaria de Estado do Trabalho, Emprego e Promoção Social e o Senac-PR, prevendo a capacitação profissional de instrutores em relação às necessidades educacionais especiais de alunos matriculados em cursos profissionalizantes; o trabalho conjunto com a Federação Nacional de Educação e Integração de Surdos (Feneis-RS) na produção e distribuição de material de apoio pedagógico destinado aos alunos surdos; a implantação do Projeto "Livro Falado", para alunos com deficiência visual, em parceria com a Secretaria de Estado da Justiça e Cidadania; o Programa "Paraná Enxergando o Futuro", da Secretaria de Estado da Saúde, que visa à triagem, encaminhamentos e provisão de recursos ópticos para alunos do Ensino Fundamental, entre outras ações.

Após pouco mais de um ano desenvolvendo um trabalho que teve como perspectiva a retomada do diálogo com representantes dos diferentes segmentos que, historicamente, colocam em prática a Educação Especial no Estado do Paraná, a fim de resgatar o princípio do trabalho conjunto e articulado entre o Poder Público e a sociedade civil, podem-se relacionar os seguintes avanços obtidos:

- O número de alunos com necessidades educacionais especiais atendidos na rede regular passa de 19.520, em dezembro de 2002, para 20.540 , em dezembro de 2003, o que significa um aumento de $6 \%$ de matrículas na rede regular no ano de 2003, em função da intensificação da oferta de apoios especializados.

- Na rede conveniada (escolas especiais) há um aumento de $9 \%$ de matrículas, no ano de 2003, uma vez que o atendimento passa de 35.172, em dezembro de 2002, para 38.190, em dezembro de 2003. 
- O número de municípios com escolas especiais passa de 349 (dez./ 2002) para 359 (dez./ 2003), sendo beneficiados mais 10 municípios (3\%) na composição da rede de atendimento especializado. Esse aumento denuncia a demanda reprimida durante os últimos anos, que deixou sem atendimento alunos com graves comprometimentos.

- Após 17 anos de vigência, há a substituição da Deliberação n. ${ }^{\circ}$ 020/ 86 pela Deliberação n. ${ }^{\circ}$ 02/03, aprovada pelo Conselho Estadual de Educação, que normatiza a Educação Especial do Paraná, de acordo com as atuais tendências legais e filosóficas mundiais.

- Pela primeira vez na história do Estado do Paraná, a Secretaria de Estado da Educação equiparou o salário de 6.883 professores que atuam na rede conveniada aos dos professores integrantes do Quadro Próprio do Magistério, o que representou um ganho salarial em média de $130 \%$, corrigindo, assim, uma defasagem e distorção histórica que dava àqueles um tratamento injusto e desigual.

- Institui-se a Resolução n. ${ }^{\circ}$ 2691/03, que define os critérios para o Convênio de Cooperação Técnica e Financeira entre a Secretaria de Estado da Educação e as instituições mantenedoras de escolas especiais.

Muitos serão ainda os desafios relacionados ao estabelecimento de políticas públicas que tragam respostas efetivas ao alcance de uma agenda inclusiva nas escolas. Mais que mencionar grandes linhas de ação que deverão ser perseguidas pelo indispensável trabalho articulado entre diferentes segmentos do Governo do Estado, é apropriado, nesse momento, enunciar as tendências e desafios a serem enfrentados a curto e médio prazos, a fim de apresentar caminhos que possam equacionar as dificuldades mais urgentes que se apresentam. Dentre as ações que nortearão o trabalho nos próximos anos, destacam-se:

- Universalização do acesso à Educação a partir da implantação do atendimento educacional especializado em 32 municípios do Estado.

- Expansão de serviços e apoios especializados a alunos com necessidades educacionais matriculados na rede regular de ensino.

- Provisão de mobiliário adaptado, materiais pedagógicos diferenciados e equipamentos específicos para apoio educacional aos alunos com necessidades educacionais especiais.

- Implantação de Centros de Atendimento e Avaliação Diagnóstica em todas as regiões do Estado. 
- Formação continuada de professores do ensino regular e especial nas diferentes áreas de atendimento.

- Elaboração e publicação de material de apoio para pais, professores, alunos e profissionais da comunidade escolar.

- Elaboração de Diretrizes Curriculares para a Educação Especial no Estado.

- Implementação de ações do Plano Estadual de Educação.

- Regulamentação de aspectos referentes à Deliberação n. ${ }^{\circ}$ 02/2003, do Conselho Estadual de Educação.

- Acompanhamento do DEE/NRE aos serviços e apoios pedagógicos especializados nas redes pública e conveniada.

- Manutenção, aperfeiçoamento e expansão do Convênio de Cooperação Técnica e Financeira, visando à universalização do atendimento.

- Estruturação interna da equipe técnico-pedagógica do DEE, a fim de aperfeiçoar o atendimento técnico-pedagógico aos apoios e serviços pedagógicos especializados e à comunidade em geral.

\section{Considerações finais}

O desafio da inclusão escolar é enfrentado pela Secretaria de Estado da Educação como uma possibilidade de repensar e reestruturar políticas e estratégias educativas, de maneira a não apenas criar oportunidades efetivas de acesso para crianças e adolescentes com necessidades educacionais especiais, mas, sobretudo, garantir condições indispensáveis para que possam manterse na escola e aprender.

Ainda que estejamos imersos no discurso oficial e hegemônico da inclusão, é necessário discutir o risco da destruição das diferenças no contexto escolar, próprios das políticas não-críticas de promoção de igualdade de direitos, que reduzem o complexo processo de inclusão social à experiência da educação escolar, entendida como mera contigüidade física dos 'diferentes' com aqueles ditos 'normais' (SOUZA; GÓES, 1999).

Obviamente, nossa meta é aquela que prevê a realização de uma escola pública de qualidade, que acolha todas as crianças, independentemente de suas condições físicas, intelectuais, sociais, emocionais, lingüísticas ou outras, tal como prevê a Declaração de Salamanca (UNESCO; MEC-ESPANHA, 1994), 
documento que inspira as políticas mundiais de inclusão na educação. No entanto, essa é uma tarefa que não depende apenas da convicção e do compromisso técnico e político dos governos, mas de pais, familiares, professores, profissionais, enfim, de todos os membros da sociedade, sob o risco de termos apenas o efeito retórico de seus benefícios para os alunos e nenhuma ação concreta e transformadora da realidade em que se encontram.

O processo de inclusão educacional exige planejamento e mudanças sistêmicas político-administrativas na gestão educacional, que envolvem desde a alocação de recursos governamentais até a flexibilização curricular que ocorre em sala de aula. Nesse processo, cada sujeito é um elemento fundamental na trama que constitui a rede que sustenta o processo inclusivo. Certamente, não se pode esperar que todos os requisitos necessários estejam prontos para que a inclusão se concretize, de fato. Do mesmo modo, não se pode estabelecer, por meio de um decreto governamental, que ela se transforme em realidade, como em um passe de mágica, do dia para a noite. Vivemos um momento de transição de paradigmas, e as conquistas já consolidadas pelas pessoas com necessidades educacionais especiais e seus familiares, como o direito à educação escolar, à reabilitação, à assistência social, não podem ser descartadas e as estruturas desmanteladas, como se não tivessem um valor histórico indiscutível na complexa rede de relações que constituem o sujeito social.

Assim, entendemos que estamos respeitando o direito constitucional da pessoa com necessidades educacionais especiais e de sua família, na escolha da forma de educação que melhor se ajuste às suas necessidades, circunstâncias e aspirações, promovendo, dessa forma, um processo de inclusão responsável e cidadã. 


\section{REFERÊNCIAS}

ARCO-VERDE, Y. F. S. Reformulação curricular no Estado do Paraná - um trabalho coletivo. In: Primeiras reflexões para a reformulação curricular da educação básica no Estado do Paraná. Curitiba: SEED/SUED, 2004. Mimeografado.

BRASIL. Ministério da Educação. Conselho Nacional de Educação. Diretrizes Nacionais para a Educação Especial na Educação Básica. Parecer CNE/CEB n. 017/2001.

COLL, C.; MARCHESI, A.; PALACIOS, J. Desenvolvimento psicológico e educação: necessidades educacionais especiais e aprendizagem escolar. Porto Alegre: Artes Médicas, 1995. v. 3.

EDLER CARVALHO, R. A nova LDB e educação especial. Rio de Janeiro: WVA, 1997.

. Removendo barreiras para a aprendizagem: educação inclusiva. Porto Alegre: Mediação, 2001.

FERREIRA, N. S. C.; AGUIAR, M. A. de S. (Orgs.). Gestão da educação: impasses, perspectivas e compromissos. São Paulo: Cortez, 2000.

MARCHESI, Á.; MARTÍN, E. Da terminologia dos distúrbios às necessidades educacionais especiais. In: COLL, C.; MARCHESI, A.; PALACIOS, J. Desenvolvimento psicológico e educação: necessidades educacionais especiais e aprendizagem escolar. Porto Alegre : Artes Médicas, 1995. v. 3.

MITTLER, P. Educação inclusiva: contextos sociais. Porto Alegre: Artmed, 2003.

PARANÁ, Conselho Estadual de Educação. Deliberação n. ${ }^{\circ}$ 02/2003.

SOUZA, R. M. de.; GÓES, M. C. R. de. O ensino para surdos na escola inclusiva: considerações sobre o excludente contexto da inclusão. In: SKLIAR, C. (Org.). Atualidade da educação bilíngüe para surdos. Porto Alegre: Mediação, 1999. v. 1-2.

TORRES, R. M. Educação para todos: a tarefa por fazer. Porto Alegre: Artmed, 2001.

UNESCO; MEC-ESPANHA. Declaração de Salamanca e linha de ação. Brasília: Corde, 1994.

Texto recebido em 12 jul. 2003

Texto aprovado em 14 set. 2003 